\title{
The Thermodynamic Analysis of Solar Heat Pump System
}

\author{
Ximing Zhang ${ }^{1, a}$, Chao Tong ${ }^{1, b}$, Shumi Zhang ${ }^{1, b}$ \\ ${ }^{1}$ School of Municipal \& Environmental Engineering, Xincheng street 5088, Changchun city, \\ Jilin province, China, Jilin Jianzhu University \\ azhangxm1999@163.com, b1844467190@qq.com
}

\begin{abstract}
Keywords: solar energy, heat pump, thermodynamics, exergy analysis
Abstract. Solar energy is a pollution-free, inexhaustible energy. The use of solar energy has been more and more widely noticed and one of the most practical technology is the solar energy heat utilization. This paper gives energy balance equations and exergy balance equations of the main instruments in a typical solar assisted heat pump system and analyzes its performance and energy efficiency based on the viewpoint of thermodynamics. This method can be used in the design and evaluation of solar assisted heat pump system.
\end{abstract}

\section{Introduction}

Today, human is facing energy and environmental problems that have become two major social problems. At present, the application of solar energy is mainly concentrated on the passive solar heating and water heater to provide domestic hot water and the development in making use of active solar energy heating system is still in its primary stage. The way of energy-saving by heat pump connected with solar energy equipment and heat storage mechanism can not only effectively overcome the scarce and discontinuity, but also achieve the goal of saving high quality energy and reducing environmental pollution. It has a great development and potential applications. The author analyzes energy balance and exergy on the basis of main equipment of solar assisted heat pump system by using the first law of thermodynamics and the second law of thermodynamics. The performance of solar assisted heat pump system and comprehensive evaluation on the energy saving effect are provided. It provides the theory basis on design and technology improvement for solar assisted heat pump system .

\section{The Solar Assisted Heat Pump System}

Heat pump is actually refrigerating machine and the difference is only the working temperature range. It absorbs heat from the surrounding environment and transfers to high temperature object to achieve heating purpose. Its characteristic is that only a small number of high quality energy is used and can be effectively extracted low quality energy from the surrounding environment. In the heating cycle, the solar collector receives low temperature heat of $10-20^{\circ} \mathrm{C}$ and makes the working medium temperature ascend to $30-50{ }^{\circ} \mathrm{C}$ through the role of heat pump. According to the solar energy and heat pump combined in different ways, it can be divided into series system and parallel system. According to the refrigerant evaporate in the collector, it can be divided into direct expansion and non-direct expansion. Typical non-direct expansion series system is developed in Qingdao according to the intensity of solar radiation and the change of heat load ${ }^{[1]}$. The author focuses on the energy balance and exergy balance of the main equipment of the system under normal operating conditions.

\section{The Analysis of Energy Balance and Exergy Balance}

Assuming that system is in a stable state, temperature is linear distribution in collector and heat exchanger. Energy loss of flow and pump power loss can be neglected. The simple working process of system is shown in Fig.1. 


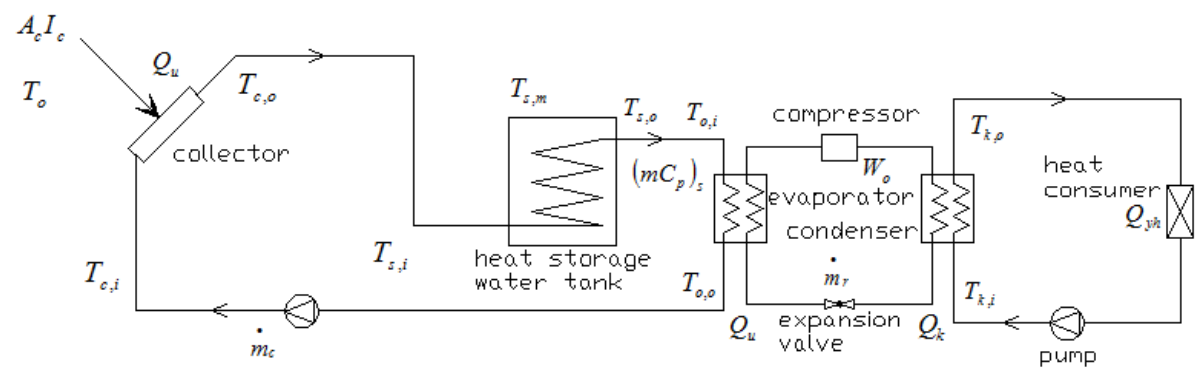

Fig.1 Schematic diagram of solar heat pump system

\section{Collector}

(1) Thermal equilibrium $Q_{u}=A_{c}\left[I_{c}(f T)-U_{c l}\left(T_{p}-T_{a}\right)\right\rfloor$

Where, $Q_{u}$ Heat of the collector, KW;

$A_{c} \_$The area of the collector, $\mathrm{m}^{2}$;

$I_{c}$ The solar radiation intensity, $\mathrm{KW} / \mathrm{m}^{2}$;

$(f T)$ _ The product of the transmittance and absorption of the collector;

$U_{c l}$ Heat loss coefficient of the collector, $\mathrm{KW} / \mathrm{m}^{2} \mathrm{~K}$;

$T_{p} \ldots$ The average temperature of collector's heat absorbing plate, $\mathrm{K}$;

$T_{a} \_$Outdoor air temperature, $\mathrm{K}$.

The thermal efficiency:

$$
\eta_{c, t}=\frac{\left(m C_{p}\right)_{c}\left(T_{c, o}-T_{c, i}\right)}{A_{c} I_{c}}
$$

Where, $\left(m C_{p}\right)_{c}$ The specific heat capacity of collector's heat-transfer fluid, $\mathrm{kW} / \mathrm{K}$;

$T_{c, i}, T_{c, o}$ The temperature of import and export of collector's heat-transfer fluid, $\mathrm{K}$.

(2) Exergy balance

$$
A_{c} I_{c}\left(1-\frac{T_{a}}{T_{s}}\right)-Q_{c l}\left(1-\frac{T_{a}}{T_{p}}\right)=m_{c}\left(e_{c, o}-e_{c, i}\right)
$$

Where, $e_{c . i}$ Import ratio exergy of heat-transfer fluid in the collector, $\mathrm{kJ} / \mathrm{kg}$;

$e_{c, o} \_$Export ratio exergy of heat-transfer fluid in the collector, $\mathrm{kJ} / \mathrm{kg}$;

$Q_{c l}$ Collector heat loss rate, $\mathrm{KW}$;

$T_{s} \_$Solar radiation temperature, $\mathrm{K}$;

$m_{c}$ _ Heat-transfer fluid flow in the collector, $\mathrm{kg} / \mathrm{s}$.

A collector exergy efficiency is defined as follows:

$$
\eta_{c, e}=\frac{m_{c}\left(e_{c, o}-e_{c, i}\right)}{A_{c} I_{c}\left(1-\frac{T_{a}}{T_{s}}\right)}
$$

\section{Heat storage water tank}

Temperature as a linear distribution in heat storage water tank.

( 1) Thermal equilibrium

$$
A_{s} U_{s l}\left(T_{s, m}-T_{a}\right)+\left(m C_{p}\right)_{s} \frac{d T_{s, m}}{d t}=\left(m C_{p}\right)_{c}\left(T_{s, i}-T_{s, o}\right)
$$

Where, ${ }^{A}{ }_{s}$ Heat storage water tank heat loss area, $\mathrm{m}^{2}$;

$U_{s l}$ Heat storage water tank heat loss coefficient, $\mathrm{KW} / \mathrm{m}^{2} \mathrm{~K}$; 


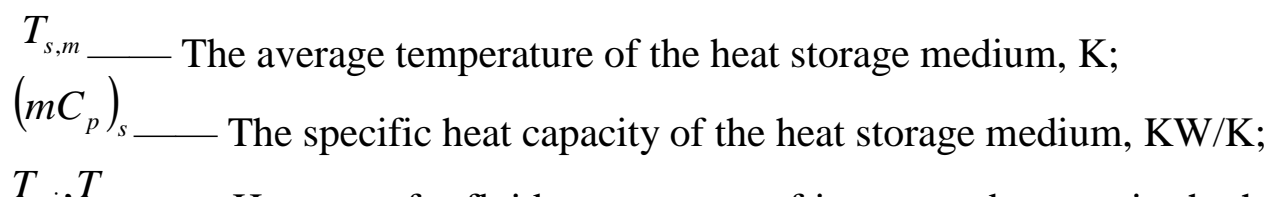

tank, K.

Thermal storage efficiency: $\eta_{s, t=} \frac{\left(m C_{p}\right)_{s} \frac{d T_{s, m}}{d t}}{\left(m C_{p}\right)_{c}\left(T_{s, i}-T_{s, o}\right)}$

(2) Exergy balance

$$
Q_{s l}\left(1-\frac{T_{a}}{T_{s, m}}\right)+Q_{s}\left(1-\frac{T_{a}}{T_{s, m}}\right)=m_{c}\left(e_{s, i}-e_{s, o}\right)
$$

Where, $Q_{s l}$ Heat loss rate of heat storage water tank, KW;

$Q_{s}$ Thermal storage rate of heat storage water tank, KW; $e_{s, i}, e_{s, o}$ The specific exergy of heat-transfer fluid import and export in the heat storage water tank, $\mathrm{kJ} / \mathrm{kg}$.

Exergy efficiency:

$$
\eta_{s, e}=\frac{Q_{s}\left(1-\frac{T_{a}}{T_{s, m}}\right)}{\left(m e_{i}\right)_{s}-\left(m e_{o}\right)_{s}}
$$

Where, $\left(m e_{i}\right)_{s},\left(m e_{o}\right)_{s}$ Exergy quantity of thermal storage fluid import and export in the heat storage water tank, $\mathrm{kJ}$.

\section{Heat pump}

(1) evaporator

(1)Thermal equilibrium $Q_{o}=m_{r}\left(h_{1}-h_{4}\right)=m_{c}\left(h_{o, i}-h_{o, o}\right)$

Where, $m_{r}$ The quality flow of the heat pump working medium, $\mathrm{kg} / \mathrm{s}$;

$\mathrm{kJ} / \mathrm{kg}$;

$h_{4}, h_{1}$ The specific enthalphy of the evaporator import and export working medium,

$h_{o, i}, h_{o, o}$ The specific enthalphy of the evaporator freeze water import and export, $\mathrm{kJ} / \mathrm{kg}$.

(2) Exergy balance $\Delta E_{o}=m_{c}\left(e_{o, i}-e_{o, o}\right)-m_{r}\left(e_{1}-e_{4}\right)$

Where, $\Delta E_{o} \longrightarrow$ The exergy loss of the evaporator, KW;

$e_{o, i}, e_{o, o}$ The specific exergy of the evaporator freeze water import and export, $\mathrm{kJ} / \mathrm{kg}$;

$e_{4}, e_{1}$ The specific exergy of the evaporator import and export working medium, $\mathrm{kJ} / \mathrm{kg}$.

Exergy efficiency:

$$
\eta_{o, e}=\frac{m_{r}\left(e_{1}-e_{4}\right)}{m_{c}\left(e_{i, o}-e_{o, o}\right)}
$$

(2) compressor

(1) Thermal equilibrium

The input theory work: $W_{O}=m_{r}\left(h_{2}-h_{1}\right) \mathrm{KW}$

Where, $h_{1}, h_{2}$ The specific enthalphy of the compressor import and export working medium, $\mathrm{kJ} / \mathrm{kg}$;

The input useful work: $W_{e}=\frac{W_{o}}{Z_{m} Z_{i} Z_{a}} \mathrm{KW}$ 
Where, achieve: ${ }^{Z_{m}}=0.85$ (mechanical efficiency $), Z_{i}=0.80$ (internal efficiency), $Z_{a}=0.96$ (electric efficiency)

(2) Exergy balance $\Delta E_{c o}=W_{e}-m_{r}\left(e_{2}-e_{1}\right)$

Where, $\Delta E_{c o}$ The exergy loss of the compressor, KW;

$e_{1}, e_{2}$ The specific exergy of the compressor import and export, $\mathrm{kJ} / \mathrm{kg}$.

Exergy efficiency:

$$
\eta_{c o, e}=\frac{m_{r}\left(e_{2}-e_{1}\right)}{W_{e}}
$$

(3) condenser

(1) Thermal equilibrium $Q_{k}=m_{r}\left(h_{2}-h_{3}\right)=m_{h y}\left(h_{k, o}-h_{k, i}\right)$

Where, $h_{2}, h_{3}$ _ The specific enthalphy of the condenser import and export working medium, $\mathrm{kJ} / \mathrm{kg}$;

$m_{\text {hy }}$ The quality flow of the condenser cooling water, $\mathrm{kg} / \mathrm{s}$;

$h_{k, i}, h_{k, o}$ The specific enthalphy of the condenser cooling water import and export, $\mathrm{kJ} / \mathrm{kg}$.

(2) Exergy balance $\Delta E_{K}=m_{r}\left(e_{2}-e_{3}\right)-m_{h y}\left(e_{k, o}-e_{k, i}\right)$

Where, $\Delta E_{K} \longrightarrow$ The exergy loss of the condenser, $\mathrm{KW}$;

$e_{k, i}, e_{k, o}$ The specific exergy of the condenser cooling water import and export, $\mathrm{kJ} / \mathrm{kg}$;

$e_{2}, e_{3} \ldots$ The specific exergy of the condenser import and export working medium, $\mathrm{kJ} / \mathrm{kg}$.

Exergy efficiency: $\eta_{k, e}=\frac{m_{h y}\left(e_{k, o}-e_{k, i}\right)}{m_{r}\left(e_{2}-e_{3}\right)}$

(4) throttle

(1) Thermal equilibrium $h_{3}=h_{4}$

Where, $h_{3}, h_{4}$ The specific enthalphy of working medium before throttle and after throttle, $\mathrm{kJ} / \mathrm{kg}$.

(2) Exergy balance $\Delta E_{v}=m_{r}\left(e_{3}-e_{4}\right)$

Where, $\Delta E_{v} \longrightarrow$ The exergy loss of the throttle, KW;

$e_{3}, e_{4}$ The specific exergy of working medium before throttle and after throttle, $\mathrm{kJ} / \mathrm{kg}$.

\section{Conclusion}

With the growth of energy demand, when the research work is carried out to a certain degree, people are more interested in how much energy-saving potential of these work. The traditional approach is heat balance with analysis method of the first law of thermodynamics. The first law of thermodynamics to analysis problem has certain limitations, and it only reflects the relationship between energy in number without revealing the energy in quality differences. While using the second law of thermodynamics to analysis, we can profoundly reveal the essence of thermal degradation during the process of energy conversion. Solar assisted heat pump system as a method of low grade energy effective utilization is gradually brought to the attention of the people. The author gives the thermal equilibrium and exergy balance equation. We can not only use solar energy heat pump system design, but also comprehensively evaluate the performance of the existing system and energy saving effect.

\section{Reference}

[1] Ximing Zhang, Yiran Zhang. The Performance of Thermal Storage Tank in Solar Energy System. Advanced Materials Research Vols. 724-725(2013) pp97-100 